\title{
Investigação qualitativa em educação: 0 professor-investigador
}

\author{
António Pedro Costa ${ }^{\mathrm{i}}$ \\ Universidade de Aveiro, Portugal \\ Lia Raquel Oliveiraii \\ Universidade do Minho, Portugal
}

\begin{abstract}
Resumo
Este texto constitui a nota introdutória ao núcleo temático deste número, dedicado à investigação qualitativa. Nele se discute a investigação qualitativa em educação e sua relação com o movimento do professor-investigador, enquanto profissional reflexivo que problematiza a prática e aprende a partir da análise da mesma, recorrendo a métodos e técnicas variados. Os cinco textos do núcleo, apresentados no $4^{\circ}$ Congresso Ibero-Americano em Investigação Qualitativa (CIAIQ2015) no Brasil, e cuja sinopse se apresenta aqui, debruçam-se sobre estudos em contexto de formação, escola, sala de aula e de análise da literatura. Eles mostram de que modo o professorinvestigador se pode tornar um cientista social que usa os resultados do conhecimento produzido para melhorar as aprendizagens dos alunos.
\end{abstract}

Palavras-chave

Investigação qualitativa; $4^{\circ}$ Congresso Ibero-Americano; Professor-investigador

A investigação qualitativa em educação tem-se projetado nos últimos 30 anos como um factor de melhoria de práticas em diversos contextos educacionais. O movimento nasceu nos anos 70 tendo como precursor Lawrence Stenhouse (citado por Norton, 2009), "who believed that all teaching should be based on research and that such research was the preserve of teachers not researchers" (p. 52). Stenhouse (2003) afirma que o professor deve ser autónomo, livre e com determinados propósitos, orientados pelo conhecimento, que articula todos os elos da sua prática, autorregulado por um "processo de investigação que é inerente ao processo de ensino e de 
aprendizagem" (p. 19). O mesmo autor e Rudduck (1985) elencavam críticas à ideia do professor-investigador, tais como:

- Os professores não sabem o que fazer

- Os professores são parciais com as descobertas da pesquisa

- Escassez de tempo para o ensino e a pesquisa

- Dificuldade de conciliar pesquisa e ensino

- Falta de esforço

Alarcão (2001) refere que "ser professor-investigador é, pois, primeiro que tudo, ter uma atitude de estar na profissão como intelectual que criticamente questiona e se questiona... Ser professor-investigador é ser capaz de se organizar para, perante uma situação problemática, se questionar intencional e sistematicamente com vista à sua compreensão e posterior solução" (p. 6).

Um professor-investigador é um questionador. As suas perguntas impulsionam para a frente (Hansen, 1997; Souza, Souza, \& Costa, 2014). O que sei sobre cada aluno e de que forma pode aprender melhor determinado conteúdo? Que apoio posso oferecer? Poderíamos elencar dezenas de perguntas, umas mais complexas do que outras que, dificilmente, seriam respondidas sem uma prática investigativa.

Nesta perspetiva deve repensar-se e reestruturar-se a formação de professores com esta orientação pela investigação, no intuito de melhorar a qualidade. Tal prática deverá constituir o uso da investigação como atitude do dia-a-dia de uma sala de aula (Galiazzi \& Moraes, 2002).

Atualmente, o professor tem ao seu alcance inúmeras ferramentas tecnológicas que lhe permitem apoiar a análise dos dados recolhidos em contexto de sala de aula. Apesar dos métodos/processos mais comuns em educação, estas ferramentas não se fecham em si mesmas, podendo o professor analisar dados provenientes de um Estudo de Caso, um Estudo Etnográfico, um Estudo Fenomenológico, entre outros. Relativamente às técnicas e métodos de recolha de dados, uma sala de aula, uma saída de campo, permite uma imensidão de formas de recolha.

Como afirmam Slomski e Martins (2008), "a cultura de investigação fundamenta-se na ideia de uma ciência educativa em que cada sala de aula é um laboratório e cada professor um membro da comunidade científica" ( $p$. 6). Por outro lado, se compreendermos que nem todos os estudos educacionais são quantificáveis e que, na maioria das vezes, interessa-nos compreender determinado fenómeno dentro de um contexto específico, a investigação qualitativa em educação proporciona ao professor métodos e técnicas fundamentais para a melhoria da prática lectiva.

Neste sentido, o Congresso Ibero-Americano em Investigação Qualitativa (CIAIQ) posiciona-se como um fórum extremamente relevante na área da 
investigação qualitativa em educação. O CIAIQ procura fomentar, através da interação, revisão, validação e publicação de qualidade, alguns destes pressupostos de melhoria da qualidade da investigação qualitativa em educação.

O $4^{\circ}$ Congresso Ibero-Americano em Investigação Qualitativa (CIAIQ2015) decorreu de 5 a 7 de agosto de 2015 na Universidade Tiradentes em Aracaju, Brasil. A conferência recebeu um total de 464 submissões de artigos, envolvendo 906 autores de 17 países. Cada artigo foi submetido a um processo de revisão double-blind realizado por uma comissão científica composta por elementos altamente qualificados nas áreas científicas do congresso.

Este núcleo temático da Revista Portuguesa de Educação (RPE) contém cinco artigos selecionados pela comissão organizadora e científica do CIAIQ2015, de entre os melhores trabalhos de investigação da conferência relacionados com Educação e, posteriormente, validados por revisores da RPE. Os artigos deste núcleo foram ampliados e aprofundados em relação aos resumos publicados nas atas do CIAIQ2015.

O primeiro artigo - Concepções sobre desenvolvimento infantil na perspectiva de educadoras em creches públicas e particulares - relata uma investigação levada a cabo no Brasil, em creches públicas e particulares, e procura levantar e discutir as conceções das educadoras sobre o construto desenvolvimento infantil. Para tal foram entrevistadas vinte e quatro educadoras (acompanhando crianças dos 24 aos 30 meses de idade), tendo os dados sido analisados mediante análise de conteúdo por categorias temáticas. Fundamentando-se na teoria sócio-histórica de Vigotski, as autoras apresentam como resultados um conjunto de categorias que vão desde as crenças adquiridas ao longo da vida até à experiência da formação inicial, passando pela interação afetiva, entre outras. Apontam para a necessidade de repensar a formação profissional de quantos trabalham na área da educação infantil, ou seja, com crianças menores de quatro anos de idade.

O segundo artigo - A teacher's tensions in a Spanish first grade two-way bilingual immersion program - localiza-se no contexto do primeiro ciclo do ensino básico no nordeste dos Estados Unidos da América e incide nas reflexões sobre as lutas diárias e tensões vividas por uma professora que leciona numa escola pública em sistema de imersão bilingue (maioria de língua inglesa e minoria de língua espanhola). As crianças falantes de inglês tornam-se bilingues no seu currículo académico, as crianças falantes de espanhol precisam de ser bilingues para manter as suas raízes culturais e linguísticas e terem sucesso num país que fala inglês. $O$ discurso e as crenças dos professores, nestes contextos, podem constituir um fator chave na defesa das minorias, promovendo ou desfavorecendo o status linguístico. Em entrevistas individuais, a professora interpretou a sua realidade no contexto da sua sala de aula. A estas entrevistas foi aplicada análise indutiva e de conteúdo. 
$O$ terceiro artigo - Critical thinking in the context of clinical practice: the need to reinvent pharmacy education - transporta-nos para o domínio da graduação em Farmácia, também nos Estados Unidos da América. Através de uma etnografia crítica, socorrendo-se de observação participante, grupos focais e entrevistas em profundidade com estudantes e professores, as autoras investigam a necessidade de aprendizagem do pensamento crítico para uma prática clínica mais próxima do paciente, como a profissão assim exige. Sustentam que o conhecimento farmacêutico tradicionalmente ensinado não é suficiente para preparar estudantes para essa prática. Pensamento crítico implica boa educação que forneça aos estudantes uma identidade social, dando forma a valores e atitudes apropriados ao grupo profissional. Entre outros resultados, a introdução de hábitos de criatividade revela-se de enorme importância para o desenvolvimento do pensamento crítico.

O quarto artigo - Inclusão no ensino superior: Percepções dos estudantes com NEE sobre o ingresso à universidade - situa-se no quadro do Ensino Superior em Portugal e debruça-se sobre os fatores que apoiam ou não a escolha e ingresso de estudantes com necessidades educativas especiais (NEE) na universidade. No caso, na Universidade de Aveiro, onde onze estudantes foram entrevistados à luz de um paradigma de investigação interpretativa. Foi questionado o seu percurso universitário, tentando identificar e compreender os fatores pessoais, educativos e socioculturais que fundamentaram as suas escolhas no acesso à universidade. Emerge a ideia de que são as melhores universidades quem se preocupa com estes estudantes e com a inclusão da diversidade em geral, constituindo esta, como curiosamente dizem as autoras, um desassossego para a instituição.

O quinto artigo - Matemática e música: Sistematização de analogias entre conteúdos matemáticos e musicais - remete-nos para uma temática cujas origens remontam à Grécia Antiga. A escola pitagórica dividiu as ciências matemáticas em quatro partes - Aritmética, Geometria, Música e Astronomia -, que viriam a ser designadas por Quadrivium, componente basilar das sete artes liberais do currículo medieval (até finais do século XV e decénios do XVI), completado com o Trivium (Gramática, Dialética e Retórica). Carecendo-se, de acordo com os autores, de literatura que elenque de forma sistemática estas relações (concretamente com os programas escolares), foi constituída esta síntese de associações que possa servir investigações futuras sobre as ligações entre matemática e música, como, por exemplo, o ensino e a aprendizagem da matemática por meio de aulas integradas de matemática e música. Com este intento, foi efetuada uma revisão, análise e sistematização qualitativa da literatura sobre as ligações entre matemática e música através de: pesquisa em repositórios de bases 
bibliográficas; consulta de manuais específicos; e sistematização das relações entre matemática e música, atendendo à organização por temas da matemática.

Finalizamos, agradecendo a todos os que de forma direta ou indireta colaboraram com o sucesso do CIAIQ2015 e com a produção deste núcleo temático, incluindo os participantes, autores, comissão organizadora e científica, apoios, equipa editorial, entre muitos outros. Através do seu interesse, participação e da qualidade e rigor do seu trabalho científico, agora publicado na Revista Portuguesa de Educação, esperamos que possa ser promovida a expansão da investigação qualitativa numa área tão relevante como é a da Investigação em Educação.

\section{Referências}

Alarcão, I. (2001). Novas tendências nos paradigmas de investigação em educação. In I. Alarcão (Org.), Escola reflexiva e nova racionalidade (pp. 135-144). Porto Alegre: Artmed Editora.

Galiazzi, M. do C., \& Moraes, R. (2002). Educação pela pesquisa como modo, tempo e espaço de qualificação da formação de professores de Ciências. Ciência \& Educação, 8(2), 237-252.

Hansen, J. (1997). Researchers in our own classrooms: What propels teacher researchers? In D. Leu, C. Kinzer, \& K. Hinchman (Eds.), Literacies for the 21st century: Research and practice (pp. 1-14). Chicago: National Reading Conference.

Norton, L. S. (2009). Action research in teaching and learning. A practical guide to conducting pedagogical research in universities (1st ed.). London and New York: Routledge. Retrieved from http://www.amazon.com/Action-Research-TeachingLearning-Universities/dp/0415468469

Slomski, V. G., \& Martins, G. de A. (2008). O conceito de professor investigador: Os saberes e competências necessárias à docência reflexiva na área contábil. Revista Universo Contábil, 4(4), 6-21.

Souza, F. N. de, Souza, D. N. de, \& Costa, A. P. (2014). Importância do questionamento no processo de investigacão qualitativa. In F. N. de Souza, D. N. de Souza, \& A. P. Costa (Eds.), Investigação qualitativa: Inovação, dilemas e desafios (1a ed.) (pp. 125-145). Aveiro: Ludomedia.

Stenhouse, L. (2003). Investigación y desarrollo del currículum (5th ed.). Madrid: Ediciones Morata.

Stenhouse, L., \& Rudduck, J. (1985). Research as a basis for teaching: Readings from the work of Lawrence Stenhouse. Heinemann.

\section{QUALITATIVE RESEARCH IN EDUCATION: THE TEACHER RESEARCHER}

\section{Abstract}

This text is an introductory note to a set of five texts with a thematic focus on qualitative research. Qualitative research in education is discussed in its articulation with the teacher researcher movement, as a movement that perceives the teacher to be a reflexive professional that problematizes practice and learns from its analysis, by resorting to a diversity of methods. A synopsis 
of each of the five texts, which were presented at the 4th Ibero-American Congress on Qualitative Research (CIAIQ2015) in Brazil, is made. The texts discuss studies undertaken in several contexts, namely teacher education, schools, classrooms, and literature review. They show how the teacher researcher can become a social scientist that uses the results from the knowledge produced in order to improve his/her students' learning.

Keywords

Qualitative research; 4th Ibero-American Congress; Teacher researcher

\section{LA INVESTIGACIÓN CUALITATIVA EN LA EDUCACIÓN: EL PROFESOR- INVESTIGADOR}

Resumen

Este texto es la nota introductoria al núcleo temático de esta edición, dedicado a la investigación cualitativa. En el núcleo temático se discute la investigación cualitativa en la educación y su relación con el desarrollo del profesorinvestigador como profesional reflexivo que cuestiona la práctica y aprende a partir del análisis de la misma, utilizando métodos y técnicas variados. Los cinco textos fundamentales que lo componen, presentados en el $4^{\circ}$ Congreso Iberoamericano de Investigación Cualitativa (CIAIC2015) en Brasil, y cuyo resumen se presenta aquí, se centran en estudios promovidos en contexto de formación, escuela, aula y revisiones de la literatura. Muestran cómo el profesor-investigador puede convertirse en un científico social que utiliza los resultados de los conocimientos generados en la investigación para mejorar el aprendizaje de los alumnos

Palabras clave

Investigación cualitativa; $4^{\circ}$ Congreso Iberoamericano; Profesor-investigador

Recebido em outubro/2015 Aceite para publicação em novembro/2015

Centro de Investigação em Didática e Tecnologia na Formação de Formadores (CIDTFF), Departamento de Educação, Universidade de Aveiro

ii Centro de Investigação em Educação, Instituto de Educação, Universidade do Minho 